\title{
Acquisition of Learning and Empathy Towards Patients in Nursing Students Through Online Escape Room: An Exploratory Qualitative Study
}

José M Rodríguez-Ferrer ${ }^{\prime}$ Ana Manzano-León (1D)

Adolfo J Cangas' José M Aguilar-Parra'

Carolina FernándezJiménez $\mathbb{( D}^{2}$ Juan M Fernández-Campoy ${ }^{3}$ Antonio Luque de la Rosa $\mathbb{D}^{3}$ Ana M Martínez-Martínez ${ }^{3}$

'Department of Psychology, University of Almería, Almería, Spain; ${ }^{2}$ Department of Psychology, University of Granada, Granada, Spain; ${ }^{3}$ Department of Education, University of Almería, Almería, Spain
Correspondence: Ana Manzano-León Department of Psychology, University of Almería, Carretera Sacramento $\mathrm{s} / \mathrm{n}$, Almería, 04I20, Spain Tel +34 640272890

Email Aml570@ual.es
Background: Currently, there are still prejudices and negative beliefs towards people with severe mental disorder. The stigma of healthcare professionals can affect both recovery time and patients' own self-stigma. In universities, it is necessary to reduce these prejudices through training on mental health.

Purpose: The purpose of this research has been to assess the use of educational escape rooms as a learning and awareness strategy on stigmatizing attitudes towards people with serious mental disorders in university students.

Methods: An online escape room has been designed whose narrative shows the daily life of a person with a serious mental illness. An exploratory qualitative study has been carried out to explore the perception of 44 university students from two Andalusian universities about this escape room.

Results: The results of the study show that most of the interviewed students consider that the educational escape room has been a fun and motivating learning strategy, which has allowed them to learn cooperatively and empathize with the protagonist with a mental disorder.

Conclusion: Online escape rooms can be a useful strategy for teaching health sciences students. Considering it a fun activity, students are more participatory and engaged to the curricular content, in our case, stigmatizing attitudes towards people with serious mental disorders.

Keywords: escape room, stigma, serious mental disorder, educational innovation, motivation, empathy

\section{Introduction}

\section{Playful Strategies}

Recently, playful strategies are being investigated in educational contexts, with the main objective of increasing student motivation and involving them in their learning processes. ${ }^{1,2}$ In addition to increasing academic motivation, the use of gamification can provide other advantages such as improving communication, social climate, participant relationships and a significant improvement in academic achievement. ${ }^{3}$

To design effective gamifications, the MDA model (Mechanics, Dynamics and Aesthetics) is used, which seeks to achieve the proposed objectives through different game elements. ${ }^{4}$ The mechanics and dynamics are the instrumental part that allow achieving objectives such as learning curricular content, skills, or competences. The aesthetics allow students to feel motivated and achieve an immersion typical of video 
games. The aesthetics envelop the entire program creating an atmosphere full of sensations and feelings that guide the action of the individuals who participate.

Following the growing success of gamification in education, the use of escape rooms in education is also developing. An escape room is an immersive cooperative adventure game. Players must exit a physical or digital room, solving a series of playful quizzes, puzzles, or challenges. ${ }^{5}$ Escape rooms have a specific narrative. For example, an apocalypse, imminent danger, a narrative based on a book, or any situation that can be motivating. Escape rooms have been shown to foster character and have a positive effect on participation and performance. ${ }^{6}$ Its main use has been to evaluate or teach curricular content, ${ }^{7,8}$ Specifically in the health field, escape rooms have been shown to be effective in facing stressful situations, consolidating basic routines and procedures. ${ }^{9-11}$

Playful strategies make it possible to achieve flow. ${ }^{12}$ Flow is a mental state of total immersion in which the person is completely focused on the activity. This immersion in which the attention is completely focused on the activity allows the processing of information in a meaningful way. To achieve this state, it is necessary to immerse yourself in the activity, which is pleasant, and the difficulty is considered by the person as a challenge. Escape rooms offer playful challenges and can promote this state of flow. ${ }^{13}$

\section{Stigma in Serious Mental Disorder}

People who are diagnosed with Serious Mental Disorder (SMI) have to cope with the impact of the diagnosis and the stigma associated with having SMI. Beliefs about people with SMI can be disabling on a social, occupational and health level. ${ }^{14}$ This series of beliefs has a negative impact on all the areas mentioned above, preventing these people from leading a normal life. ${ }^{15,16}$ The prejudices about this group are that they are dangerous, unstable, vague and even that they are responsible for their own disorder. ${ }^{17,18}$

This set of beliefs imply that people identify with them through an internalization process, identified as selfesteem. People with SMI see their life even more limited by their own beliefs about themselves. ${ }^{19}$

In previous studies, it has been possible to verify that the healthcare workers who attend this population group have the same level of prejudice about this group and their beliefs influence the clinical judgment of professionals. ${ }^{14}$
Furthermore, it has been shown that stigma on the part of healthcare personnel influences recovery time. ${ }^{15}$

Previous experiences have shown that it is possible to reduce people's stigma through forums, talks or direct contact. $^{20}$ In the video game industry, several video games have been designed with a narrative in which people with a mental disorder appear, for example The Town of Light, Hellblade: Senua's Sacrifice and Celeste, seeking user awareness and empathy. ${ }^{21}$

However, there is little research that evaluates the impact on the sensitization of these products in the players. Recently, it has been investigated that virtual reality and serious gaming could be beneficial to reduce stigma. For example, Stigma-Stop ${ }^{22,23}$ is a virtual game whose purpose is to sensitize participants about serious mental disorder. Participants must network and collaborate with 4 characters with SMI to win the game. After interacting with each of the characters, another mini games appear in which it is necessary to highlight the positive aspects of that person with SMI. In this game, the characters also show prototypical behaviors of people with SMI, which makes it easier to identify them in real life.

Following the research on the awareness of university students through playful strategies, this study starts from the need to deepen the application of online escape rooms to reinforce the subject about Mental Health in healthcare degrees. The research questions are: (1) How do university students perceive escape rooms? (2) Are escape rooms beneficial for the learning of university students of healthcare degree? (3) Are escape rooms useful to sensitize students about prejudices towards people with severe mental disorders?

\section{Materials and Methods \\ Participants}

This research was carried out with students from the Faculty of Healthcare of two Andalusian universities. An educational escape room to raise awareness of serious mental disorder was implemented as part of their academic curriculum.

A total of 197 students participated in the online escape room during the 2020/2021 academic year. Once the escape room was completed, each student was voluntarily offered to answer an online survey of open questions. This survey was completed by a total of 44 students $(22 \%$ of the participants), 29 women and 15 men, aged between 19 and 38 years $(M=24.73 ; S D=7.48)$. 
To select the participating students, a convenience sample was chosen. The inclusion criterion was the willingness to participate in the escape room organized by the teachers and the researchers and the willingness to fill in the final survey.

Before data collection, students were informed about the nature of the study, assured of their anonymity, and gave their written consent. The final evaluation was carried out by the class teachers according to written instructions. Students completed the questionnaire during a regular class.

The entire process was carried out in accordance with the Declaration of Helsinki. ${ }^{24}$ All participants also gave their oral and written informed consent for their participation in the study and subsequent publication of anonymous responses. Ethical approval was obtained from the Research Ethics Committee of the University of Almería (Ref. UALBIO 2021/01).

\section{Procedure}

The escape room was designed and executed for the subject "Mental Health" in the first year of the Nursing degree at two Andalusian universities. The application of the escape room was carried out jointly between the teacher coordinating the subject and two professionals from the research team. Prior to the application, two teachers were trained on playful methodologies and the necessary resources were designed.

Due to the proposed sanitary measures due to COVID19 , the escape room was designed online. The objective of the online escape room was to reinforce the learning of the contents about serious mental disorder in a motivating way.

To carry out the escape room, a bibliographic review on prejudices about mental health was carried out. In addition, interviews were conducted with people affected by SMI and professionals who work with these people, such as psychologists and nurses. It was concluded that these people suffered discrimination in their social, work and health environment. The experiences narrated by these people helped create the narrative and game elements that these experiences contained. Thus, the escape room sought to reflect the context and specific situations in which people with SMI experience discrimination. Additionally, the escape room included information on SMI medication and its side effects.

The escape room was made with the Genial.ly digital platform. It was chosen to facilitate distribution by different universities. Before starting the escape room, the students had to go through an explanatory tutorial to understand the operation of the platform. The escape room images were designed through the FreePik resource bank with a Premium license.

Regarding the game design of the escape room, it has a linear structure. Solving one clue will give the object to solve for the next clue, and so on and so forth until the students escape. Tasks in a linear room must be solved in a particular order.

It was carried out online and synchronously. The average duration of the escape room was 60 minutes. The university's learning platform was used to post the Genial.ly link with the escape room and solve it in online rooms. The students had to solve it in teams of 4 people. Each of these groups was in a separate room where the teacher and the researchers could enter to answer questions or give clues. The students were offered all the clues they requested. This decision was made because it is important that all students finish the escape room so that they have all the information about the content taught (prejudices and self-stigma towards people with SMI, medication of mental health patients and leisure as a protective factor for Mental health).

The escape room narrative involves waking up in a room without any memories of who or where you are. You must overcome different challenges until you know that your name is Enrique, you have a serious mental disorder, and you have a normal life (You have a job, you pay bills for your apartment, you take medication, and you are going to have a date with a friend).

The design of the different tasks of the escape room was (See Figure 1):

\section{- Computer}

In this room there were elements hidden around the room (click and point) that allow knowing the password of a computer. Inside this computer there is information about Enrique (social networks, notes and browsing history). Access to the computer allows to solve the following task for the following tests. Also, on the computer were links to two awareness videos on severe mental disorder.

- Diary and mobile phone

Through a code hidden in the diary, the mobile can be accessed. Conversations with the hospital's nurses, psychologists, family, and friends can be read on Enrique's mobile phone. These conversations reflect the concerns and limited relationships that Enrique has. Some responses to his messages can be interpreted as condescension, 


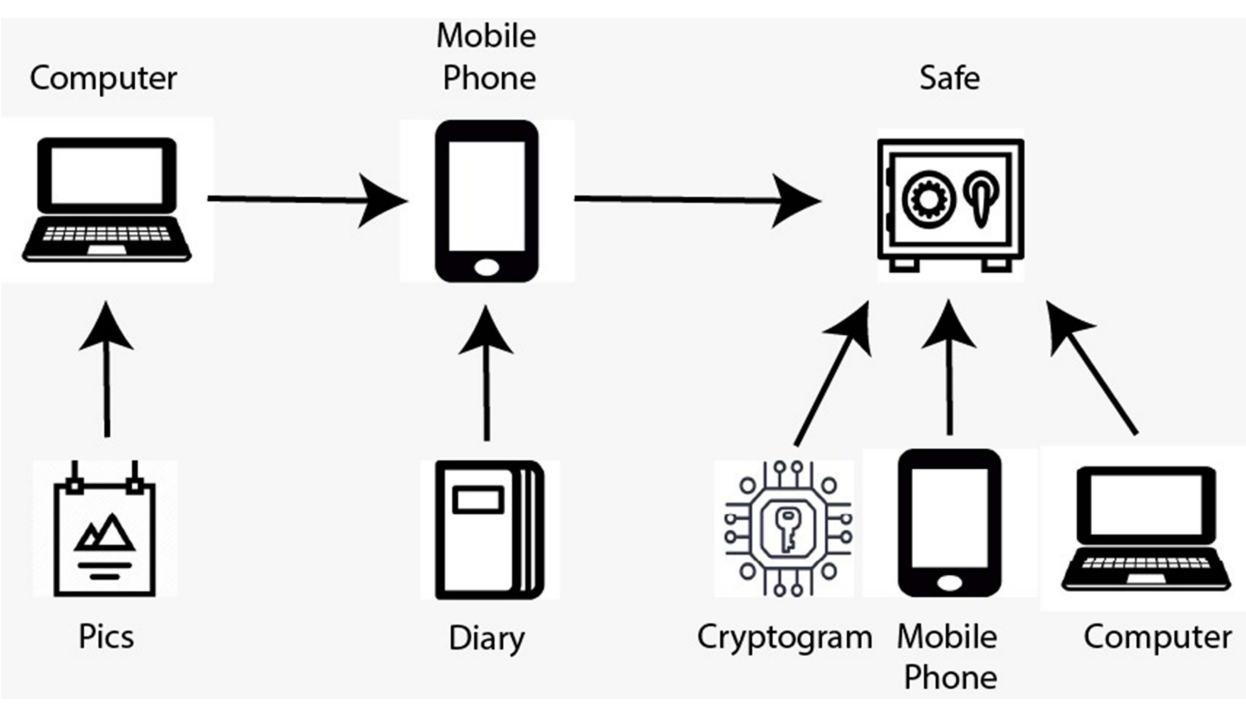

Figure I Escape room flowchart.

childishness, and other behaviors that people with SMI reported in previous interviews. Conversations with nurses and healthcare personnel reflect the side effects that medication can have on these people, such as difficulties in sexual and emotional life. It is also narrated how these people may have a perception of the world different from the norm.

- Safe and door

The safe is opened by means of a phrase that is encoded in the computer. To decode it, it will be necessary to find the decoding key found in one of the rooms. This coded information allows the safe to be opened using information contained in the mobile phone and in the bedroom.

The box finally gives you the key to get out the door. When you click the door again, there is a conclusion message. This message gives statistical information about SMI and the possibility that the player may have an SMI in the future.

All this information was told as a first-person story. In this way, the protagonist was allowed to "remember" who he was and that he needed to leave home to have a date with an important person. In a synthetic way, the escape room is a first-person investigation of the protagonist.

\section{Data Collection}

The general objective of the study was to explore and describe the assessment of the health sciences students on the experience of performing an educational escape room to raise awareness of mental disorders. The design was exploratory and descriptive, based on the qualitative methodology. ${ }^{25}$

The data for this study was collected between October 2020 and March 2021. The permission to collect data was requested in writing from participating students who voluntarily filled out the open-ended survey after participating in the escape room.

The university teachers of the subjects where the escape room was applied received written information about the purpose of the study and how it would be carried out. The 44 students who chose to participate in the study were asked to answer an online survey conducted with Google Forms where they were asked to describe their experience and answer the following questions: "What did you think of the escape room?" "Would you recommend to other students to participate in the escape room, why?" "What did you like the most about the escape room?" "What would you improve on the escape room?" and "Do you have any additional comments about the escape room?". These questions were openended, so that the students could answer freely and thus favor a deeper exploration of their answers. ${ }^{26}$

The participants reported their opinions on the use of educational escape rooms and answered the survey questions, previously accepting their consent to participate. The email of one of the principal investigators was added in case they had questions or suggestions about the study.

\section{Data Analysis}

All the surveys were grouped in the same document for transcription. All quotations cited in this document have 
been supported and analyzed by the ATLAS.ti software (version 8.4.2, ATLAS.ti Scientific Software Development $\mathrm{GmbH}$, Berlin, Germany), then translated from Spanish to English from transcripts.

After collecting the transcript, open coding was performed first. It consists of a careful examination of the data to identify the meaning of the students' responses. To ensure the validity and thoroughness of the analysis, two researchers separately recorded the first open codes exposing the thoughts and meanings of the surveys. Then, these two researchers combined their codes and unified or divided one of them if necessary. In case of doubts about the interpretation, the help of a third investigator was requested. In this phase, the categories and subcategories were related. Finally, the categories were organized into a network of relationships or concept map. Structural networks or flow diagrams graphically represent possible structures or systems of relationships between categories or codes. This phase was also carried out from the discussion of two researchers, and, in case of disagreement, a third researcher was contacted.

\section{Results}

After the analysis of the interviews conducted with the nursing students, the following categories were identified (See Tables 1-3).

\section{Escape Room Design}

The elements of this gamification have been the game mechanics (challenges and tasks related to the curricular content) and narrative.

On the one hand, several students mention that the escape room was complex but that despite this, they were able to escape. The goal of preparing a challenging but achievable design was to achieve flow status and increase motivation. The design of these elements has been valued positively to favor the autotelic experience or flow experience and they have been considered fun.

On the other hand, the narrative stands out as an immersive and enjoyable element. In educational escape rooms, the immersive experience is very important to motivate students. For the experience to be credible, it is necessary that the narrative and the challenges are connected to the educational message to convey.

\section{Empathy and Learning}

The main objective of the educational escape rooms is to create an immersive learning environment, where game elements are incorporated to work on the educational and social purposes proposed by the teacher. The results of the survey show how students have perceived the escape room as a motivating way of learning the contents of the subject and specially how it has helped them to become aware of

Table I Main Category I: Escape Room Design

\begin{tabular}{|c|c|c|c|}
\hline $\begin{array}{l}\text { Main } \\
\text { Category }\end{array}$ & $\begin{array}{l}\text { Sub- } \\
\text { Category }\end{array}$ & $\begin{array}{l}\text { Number of } \\
\text { Statements }\end{array}$ & Examples of Statements \\
\hline \multirow[t]{4}{*}{$\begin{array}{l}\text { Escape } \\
\text { room }\end{array}$} & $\begin{array}{l}\text { Gamification } \\
\text { elements }\end{array}$ & $\begin{array}{l}41 \text { from } 44 \text {, } \\
93.18 \%\end{array}$ & $\begin{array}{l}\text { What I liked the most was the narrative ... the fact of getting to know the character little by } \\
\text { little while you were playing. (SI7) } \\
\text { I have really enjoyed the challenges. Our team had to think a lot about how to open each lock, } \\
\text { but we managed to get Enrique out. (S20) }\end{array}$ \\
\hline & Fun & $\begin{array}{l}40 \text { from } 44 \text {, } \\
90.91 \%\end{array}$ & $\begin{array}{l}\text { It has been super fun and entertaining, it's great to be able to do these activities from time to } \\
\text { time. (S36) } \\
\text { I have found the way in which they have proposed to teach us very funny. I wish we could repeat } \\
\text { it! (S4I) }\end{array}$ \\
\hline & Motivation & $\begin{array}{l}36 \text { from } 44 \text {, } \\
81.82 \%\end{array}$ & $\begin{array}{l}\text { Everything in general has motivated me, both the way in which you have to look for the clues } \\
\text { and the story. It would be very useful for those people who do not take into account mental } \\
\text { illness and who unfortunately suffers a large part of the population. (SI) } \\
\text { I found it very funny and motivating, the truth is that you are so focused that you do not realize } \\
\text { what is happening around you. (S43) }\end{array}$ \\
\hline & Flow & $\begin{array}{l}34 \text { from } 44 \text {, } \\
77.27 \%\end{array}$ & $\begin{array}{l}\text { I have felt the need to know what was happening and how to end the escape room. It has } \\
\text { thrilled me. (S8) } \\
\text { The narrative has made us forget everything else and want to keep playing to help Enrique. (S44) }\end{array}$ \\
\hline
\end{tabular}

Note: S (which stands for student) and a number (which was chosen for each student in a linear order). 
Table 2 Main Category 2: Empathy and Learning

\begin{tabular}{|l|l|l|l|}
\hline $\begin{array}{l}\text { Main } \\
\text { Category }\end{array}$ & Sub-Category & $\begin{array}{l}\text { Number of } \\
\text { Statements }\end{array}$ & Examples of Statements \\
\hline $\begin{array}{l}\text { Empathy } \\
\text { and } \\
\text { Learning }\end{array}$ & $\begin{array}{l}\text { Empathy with the character and } \\
\text { understanding of mental health }\end{array}$ & $\begin{array}{l}35 \text { from } 44, \\
79.54 \%\end{array}$ & $\begin{array}{l}\text { You empathize with Enrique almost without realizing it. (SI5) } \\
\text { This escape room has helped me learn about people with mental illness, and } \\
\text { especially disprove hoaxes from the movies. (SI I) }\end{array}$ \\
\cline { 2 - 5 } & Educative innovation & $\begin{array}{l}\text { II from 44, } \\
25 \%\end{array}$ & $\begin{array}{l}\text { Learning like this has been something different. Being able to interact and put } \\
\text { oneself in Enrique's shoes has been very different and innovative. (S6). } \\
\text { It has been an educational proposal very different from what we are used to, } \\
\text { and I have loved it. (S3) }\end{array}$ \\
\cline { 2 - 5 } & Teamwork & $\begin{array}{l}8 \text { from } 44, \\
18.18 \%\end{array}$ & $\begin{array}{l}\text { (What I liked the most was) the teamwork and the originality of the activity. I } \\
\text { have had a great time with my friends and the video that we have seen on } \\
\text { YouTube has made my hair stand on end because I did not expect it at all, it has } \\
\text { been super interesting. (S34). } \\
\text { It is quite achieved and looks totally like an escape room. I have been to several } \\
\text { in person, and it has been quite like the normal ones. In the group we have } \\
\text { helped each other, and we have solved it together so that no one is left behind. } \\
\text { (S9) }\end{array}$ \\
\cline { 2 - 5 } & $\begin{array}{l}\text { Information and Communication } \\
\text { Technologies (ICT) }\end{array}$ & $\begin{array}{l}4 \text { from } 44, \\
9.09 \%\end{array}$ & $\begin{array}{l}\text { I liked learning about mental illness in an interactive way. (S5) } \\
\text { I liked that the game is interactive, and we can play and learn. (S32) }\end{array}$ \\
\hline
\end{tabular}

Note: S (which stands for student) and a number (which was chosen for each student in a linear order).

Table 3 Main Category 3: Improvement Proposals

\begin{tabular}{|l|l|l|l|}
\hline $\begin{array}{l}\text { Main } \\
\text { Category }\end{array}$ & Sub-Category & $\begin{array}{l}\text { Number of } \\
\text { Statements }\end{array}$ & Examples of Statements \\
\hline $\begin{array}{l}\text { Improvement } \\
\text { proposals }\end{array}$ & $\begin{array}{l}\text { Continuity of } \\
\text { innovative practices }\end{array}$ & $\begin{array}{l}4 \text { from 44, } \\
9.09 \%\end{array}$ & $\begin{array}{l}\text { It would not improve anything. I would like there to be more escape room to be able } \\
\text { to repeat the experience in classroom. (SI) } \\
\text { Activities like this should be done more often, it brings us closer to the reality that } \\
\text { we will see in the hospitals. (S37) }\end{array}$ \\
\cline { 2 - 4 } & More duration & $\begin{array}{l}3 \text { from 44, } \\
6.83 \%\end{array}$ & $\begin{array}{l}\text { (I wish it were) longer. I had a lot of fun, great! (S3) } \\
\text { The activity could be longer. (S38) }\end{array}$ \\
\cline { 2 - 4 } & More clues & $\begin{array}{l}3 \text { from 44, } \\
6.83 \%\end{array}$ & $\begin{array}{l}\text { It seemed complex to me; with more clues it would be easier. (S6) } \\
\text { A script of clues would have helped us to solve it in less time because we would not } \\
\text { have been stuck. (S40) }\end{array}$ \\
\cline { 2 - 4 } & Greater difficulty & $\begin{array}{l}\text { I from 44, } \\
2.27 \%\end{array}$ & I liked it but maybe I would put more problems to make it longer. (SI2) \\
\hline
\end{tabular}

Note: S (which stands for student) and a number (which was chosen for each student in a linear order).

serious mental disorder. Students also indicated that they were motivated and enjoyed working as a team.

\section{Improvement Proposals}

One of the survey questions was to mention what could be improved in the escape room. It should be noted that many students wrote that they would not improve anything, as they had liked the experience. However, any educational activity has a range of improvement. Within this category, the subcategories found were continuity of recreational activities $(9.09 \%)$, longer duration of the escape room $(6.83 \%)$, more tracks $(6.83 \%)$ and increasing difficulty $(2.27 \%)$.

\section{Discussion}

This research reports the results of an exploratory qualitative study on educational escape rooms in subjects from the Faculty of Health Sciences at a higher education institution. 
These results provide information on the students' assessment of educational escape rooms for their learning process and to raise awareness about the stigma towards people with severe mental disorders. Based on these results, it can be suggested that the appropriate design and use of educational escape rooms can have a positive impact on the motivation, flow, and perceived learning of university students.

The findings on academic motivation are related to the results of previous research, ${ }^{27-29}$ and reaffirm that escape rooms favor student participation. These results have appeared in the reports of both men and women, so it can be considered that escape rooms can be effective for both sexes.

A novel and relevant finding of this study is that it provides significant data on the opportunity to design escape rooms that favor empathy and awareness in students. The ability to empathize and be sensitive to people with severe mental disorders is important for students in the social and health area as future professionals who will deal with these patients. ${ }^{30}$ Little research has been done to address stigma awareness in university students with playful strategies, ${ }^{22}$ so this work makes an important contribution to this growing field of research by reporting a success case in which a such an escape room in a higher education setting.

Due to the COVID-19 pandemic, educational institutions had to make an urgent shift from face-to-face education to online education or towards hybrid models. One of the reasons the escape room was designed online was so that any student could do it, even though they were confined. Thanks to the positive comments received in the escape room, it can be affirmed that online escape rooms can be a valuable educational resource that can be hosted on the Blackboard or another educational platform. In addition, online escape rooms are highly reusable for the following years. ${ }^{31}$

\section{Limitations}

The results of this study represent the responses of fortyfour college students. A possible limitation of this study is the limited number of respondents. Furthermore, as it was not an interview, it was not possible to delve into the students' responses that could offer a greater perspective and reflection on the use of escape rooms in the classroom. Another limitation of the study is the lack of a combination of qualitative and quantitative methods that would improve the validity of the research. Due to this, future studies are needed that deepen the capacity of playful strategies, such as escape rooms, to promote awareness and learning of university students.

\section{Further Studies}

New studies need to be developed on playful learning strategies that can be developed at the university level. This could potentially be helpful in building the motivation, professional skills, and awareness necessary for professional development.

An interesting aspect that deserves a more in-depth study is to delve into which are the game elements that most motivate students and make a comparison between different playful strategies such as gamification, gamebased learning, and escape rooms. Another question that could be studied further is whether escape rooms could be effective in raising awareness of other vulnerable groups.

\section{Conclusion}

The results of this study show how college students felt about an educational escape room for awareness and learning about severe mental disorder. The students were generally satisfied with the escape room and only expressed the need for some minor changes in the program, one of them being that these types of activities are not punctual and that they remain in the academic programs. This shows that students show a great interest in innovative and playful teaching methodologies where they can learn in a practical and fun way, work and collaborate with each other and feel that they have achievable challenges.

\section{Disclosure}

The authors report no conflicts of interest in this work.

\section{References}

1. Kalogiannakis M, Papadakis S, Zourmpakis A-I. Gamification in science education. a systematic review of the literature. Edu Sci. 2021;11(1):22. doi:10.3390/educsci11010022

2. Prieto Andreu JM. Una revisión sistemática sobre gamificación, motivación y aprendizaje en universitarios (A systematic review of gamification, motivation and learning in university students). Teor de la Educ Rev Interuniversitaria. 2020;32(1):73-99. doi:10.14201/ teri. 20625

3. Saleem AN, Noori NM, Ozdamli F. Gamification applications in E-learning: a literature review. Technol Knowl Learn. 2021. doi:10.1007/s10758-020-09487-X

4. Kusuma GP, Wigati EK, Utomo Y, Putera Suryapranata LK. Analysis of gamification models in education using MDA framework. Procedia Comput Sci. 2018;135:385-392. doi:10.1016/j.procs.2018.08.187

5. Veldkamp A, Van De Grint L, Knippels M-C, Van Joolingen W. Escape education: a systematic review on escape rooms in education. Edu Res Rev. 2020;31:100364. doi:10.1016/j.edurev.2020.100364 
6. Xu Y, Lau Y, Cheng LJ, Lau ST. Learning experiences of game-based educational intervention in nursing students: a systematic mixedstudies review. Nurse Educ Today. 2021;107:105139. doi:10.1016/j. nedt.2021.105139

7. Makri A, Vlachopoulos D, Martina RA. Digital escape rooms as innovative pedagogical tools in education: a systematic literature review. Sustainability. 2021;13(8):4587. doi:10.3390/su13084587

8. Barba-Martín RA, Bores-García D, Hortigüela-Alcalá D, GonzálezCalvo G. The application of the teaching games for understanding in physical education. systematic review of the last six years. Int $J$ Environ Res Public Health. 2020;17(9):3330. doi:10.3390/ ijerph17093330

9. McLaughlin JL, Reed JA, Shiveley J, Lee S. Escape room blueprint: central orientation contagion crisis. Simul Gaming. 2021;52(1):2430. doi:10.1177/1046878120954493

10. San Martin L, Walsh H, Santerre M, Fortkiewicz J, Nicholson L. Creation of a "Patient" hospital escape room experience to reduce harm and improve quality of care. J Nurs Care Qual. 2021;36(1):3842. doi:10.1097/NCQ.0000000000000485

11. Brown N, Darby W, Coronel H. An escape room as a simulation teaching strategy. Clin Simul Nurs. 2019;30:1-6. doi:10.1016/j. ecns.2019.02.002

12. Csíkszentmihályi M. Flow: Psychlogie van de Optimale Ervaring. VBK Media; 2020.

13. Lien Y, Wang C, Wang S, Li C, Hou H. Designing an escape room educational game and a game-based learning activity for science learning: analysis of learning achievement and flow state. 2019 8th International Congress on Advanced Applied Informatics (IIAI-AAI); 2019:1049-1050.

14. Corrigan PW, Mittal D, Reaves CM, et al. Mental health stigma and primary health care decisions. Psychiatry Res. 2014;218(1-2):35-38. doi:10.1016/j.psychres.2014.04.028

15. Deluca JS. Conceptualizing adolescent mental illness stigma: youth stigma development and stigma reduction programs. Adolesc Res Rev. 2020;5(2):153-171. doi:10.1007/s40894-018-0106-3

16. Galán Casado D, Castillo Algarra J, García Tardón B. Deporte e Inclusión social en personas con Trastorno Mental Grave (TMG) (Sports and social inclusion for people with severe mental illness (SMI)). Psychol Soc Educ. 2020;12(1):71. doi:10.25115/psye. v0i0.2343

17. Brine K, Power J, Smith HP, Nolan A. A qualitative study of success in postrelease federal inmates with mental health issues. $J$ Correct Health Care. 2021;27(1):40-50. doi:10.1089/jchc.19.02.0009

18. Zhang Y, Kuhn SK, Jobson L, Haque S. A review of autobiographical memory studies on patients with schizophrenia spectrum disorders. BMC Psychiatry. 2019;19(1):361. doi:10.1186/s12888-019-2346-6

19. Macías FJS. Cómo encontrar un lugar en el mundo: explorando experiencias de recuperación de personas con trastornos mentales graves (Finding a place in the world: Exploring recovery experiences of people with severe mental illness). Hist Cienc Saude Manguinhos. 2011;18(1):121-139. doi:10.1590/s010459702011000100008

Psychology Research and Behavior Management

\section{Publish your work in this journal}

Psychology Research and Behavior Management is an international, peer-reviewed, open access journal focusing on the science of psychology and its application in behavior management to develop improved outcomes in the clinical, educational, sports and business arenas. Specific topics covered in the journal include: Neuroscience, memory and decision making; Behavior modification and management; Clinical
20. Corrigan PW, Morris SB, Michaels PJ, Rafacz JD, Rüsch N. Challenging the public stigma of mental illness: a meta-analysis of outcome studies. Psychiatr Serv. 2012;63(10):963-973. doi:10.1176/ appi.ps.201100529

21. Paredes Otero G. El enemigo invisible: la sensibilización ante las enfermedades mentales a través de los videojuegos (The invisible enemy: Raising awareness of mental illness through video games). Barataria Revista Castellano-Manchega de Ciencias Sociales. 2020;29:69-83. doi:10.20932/barataria.v0i29.565

22. Mullor D, Sayans-Jimenez P, Cangas AJ, Navarro N. Effect of a serious game (Stigma-Stop) on reducing stigma among psychology students: a Controlled Study. Cyberpsychol Behav Soc Netw. 2019;22 (3):205-211. doi:10.1089/cyber.2018.0172

23. Cangas AJ, Navarro N, Parra JMA, et al. Stigma-stop: a serious game against the stigma toward mental health in educational settings. Front Psychol. 2017;8. doi:10.3389/fpsyg.2017.01385

24. (WMA) WMA. WMA Declaration of Helsinki - Ethical Principles for Medical Research Involving Human Subjects; 2018. Available from: https://www.wma.net/policies-post/wma-declaration-of-hel sinki-ethical-principles-for-medical-research-involving-human-sub jects/. Accessed December 31, 2021.

25. Taylor S, Bogdan R. Introducción a los métodos cualitativos de investigación: La búsqueda de significados (Introduction to qualitative research methods: The search for meanings). Grupo Planeta; 1987.

26. Guerrero Bejarano MA. La Investigación Cualitativa (Qualitative investigation). INNOVA Res J. 2016;1(2):1-9.

27. Gómez-Urquiza JL, Gómez-Salgado J, Albendín-García L, CorreaRodríguez M, González-Jiménez E. The impact on nursing students' opinions and motivation of using a "Nursing Escape Room" as a teaching game: a descriptive study. Nurse Educ Today. 2019;72:7376. doi:10.1016/j.nedt.2018.10.018

28. Macías-Guillén A, Díez RM, Serrano-Luján L, Borrás-Gené O. Educational hall escape: increasing motivation and raising emotions in higher education students. Edu Sci. 2021;11(9):527. doi:10.3390/ educsci11090527

29. Manzano-León A, Rodríguez-Ferrer JM, Aguilar-Parra JM, et al. Escape rooms as a learning strategy for special education master's degree students. Int J Environ Res Public Health. 2021;18(14):7304. doi:10.3390/ijerph18147304

30. Gholamzadeh S, Khastavaneh M, Khademian Z, Ghadakpour S. The effects of empathy skills training on nursing students' empathy and attitudes toward elderly people. BMC Med Educ. 2018;18(1):198. doi:10.1186/s12909-018-1297-9

31. Cain J. Exploratory implementation of a blended format escape room in a large enrollment pharmacy management class. Curr Pharm Teach Learn. 2019;11(1):44-50. doi:10.1016/j.cptl.2018.09.010 applications; Business and sports performance management; Socia and developmental studies; Animal studies. The manuscript management system is completely online and includes a very quick and fair peer-review system, which is all easy to use. Visit http://www. dovepress.com/testimonials.php to read real quotes from published authors. 